Braz. J. vet. Res. anim. Sci.,

Säo Paulo, v.3I, n.3/4, p.216-20, 1994.

\title{
CONTROLE ESTRATÉGICO EXPERIMENTAL DO CARRAPATO DE BOVINOS Boophilus microplus (CANESTRINI, 1887) (ACARINA: IXODIDAE) EM BEZERROS DO MUNICÍPIO DE VIÇOSA, ZONA DA MATA DE MINAS GERAIS, BRASIL*
}

\author{
EXPERIMENTAL ESTRATEGIC CONTROL OF THE CATTLE-TICK Boophilus microplus (CANESTRINI, 1887) \\ (ACARINA: IXODIDAE) IN CALVES FROM VIÇOSA, ZONA DA MATA, MINAS GERAIS, BRAZIL
}

\author{
Jackson Victor de ARAUJO'
}

\section{RESUMO}

\begin{abstract}
Na microrregião de Viçosa-MG, foi testado um controle estratégico experimental do carrapato de bovinos Boophilus microplus em bezerros 3/4 Holandês $\times$ Zebu pela administração do Amitraz, de outubro de 1990) a fevereiro de 1991, em cinco banhos intervalados de 28 dias. () controle estratégico apresentou efeito redutor sobre o número de formas adultas de Boophilus microplus nos animais tratados. mas não foi suficiente para impedir que estes níveis se elevassem após o início de condiçōes meteorológicas satisfatórias para o desenvolvimento de carrapato na primavera de 1991.
\end{abstract}

UNITERMOS: Carrapatos; Boophilus microplus; Controle de pestes; Bezerros; Brasil

\section{INTRODUÇÃO}

Virtualmente, todo o território brasileiro está infestado ou tem condições ambientais físicas favoráveis para o desenvolvimento de Boophilus microplus, a principal espécie de carrapato que ectoparasita bovinos no país ${ }^{3}$.

O Ministério da Agricultura calculou que as perdas ocasionadas por carrapatos sobre o rebanho bovino, em 1993, foram de 1 bilhão de dólares ${ }^{2}$. Estas perdas são exacerbadas em rebanho leitciro, quando há aumento do grau de sangue de raças européias, com conseqüente queda da resistência natural dos bovinos às infestações por carrapatos.

Nas campanhas contra este parasita, o Brasil apresenta desvantagens por possuir grande extensão territorial, muitas regiões com infra-estrutura pouco desenvolvida e extensas frontciras com outros países igualmente infestados. Além disso, o controle tem sido realizado pela aplicação empírica de carrapaticidas, às vezes sem orientação técnica ${ }^{4}$.

O presente trabalho tem o objetivo de estudar o controle estratégico do Boophilus microplus em bovinos na microrregião de Viçosa-MG, através do tratamento com o Amitraz.

\section{MATERIAL E MÉTODO}

O experimento foi conduzido no Município de Viçosa, Estado de Minas Gerais, com latitude de $20^{\circ} 45^{\prime} 20^{\prime \prime} \mathrm{S}$, longitude de $42^{\circ} 52^{\prime} 40^{\prime \prime} \mathrm{W}$ e altitude de $649 \mathrm{~m}$, no período de março de 1990 a dezembro de 1991 .
Quinze bezerros 3/4 Holandês x Zebu entre sete meses e um ano de idade e livres de carrapato foram transferidos para pastagens de capim gordura (Melinis minutiflora) no final do período chuvoso (março de 1990), onde permaneceram por quatro meses, com 15 fêmeas adultas e naturalmente infestadas pelo Boophilus microplus para estabilizar a população de carrapatos. Os bovinos adultos foram então retirados (junho de 1990) e apenas permaneceram os bezerros, que foram divididos em dois grupos, com taxa de lotação de 0,6 animais/ ha nos piquetes de cada grupo.

O Grupo I, estratégico, foi constituído por nove animais (três machos e seis fêmeas). Os animais receberam cinco banhos de aspersão com acaricida à base de Amitraz $z^{* *}[\mathrm{~N}, \mathrm{n}$-bis $(2,4-$ dimetilfenilimino-metil-metilamina)]. Foram utilizadas bombas aspersoras contendo 1 litro do produto para 500 litros d'água. Os banhos foram aplicados a intervalos de 28 dias, no período de 18 de outubro de 1990 a 7 de fevereiro de 1991. Cada bezerro recebeu 5 litros da solução a cada banho.

O Grupo II,controle, foi constituído por seis animais (dois machos e quatro fêmeas) que não receberam banhos de carrapaticida.

Os banhos nos animais do Grupo I foram baseados em estudos de sazonalidade, feitos por FONSECA (trabalho não publicado)*** nos anos de 1984 a 1989 em Viçosa, e pelo acompanhamento das contagens de carrapatos efetuadas nos bezerros dos dois grupos até o primeiro banho.

I - Professor Assistente - Universidade Federal de Viçosa-MG

- Trabalho financiado pelo CNPq

*."Triatox (COOPERS do Brasil S.A.)

-" Variaçăo sazonal do Boophilus microplus em Viçosa - MG. A.H. FONSECA. com financiamento do CNPq (Em fase de elaboraçāo) 
As contagens dos carrapatos, fêmeas ingurgitadas acima de $4,5 \mathrm{~mm}$, foram feitas a cada 14 dias tomando-se o lado esquerdo de cada animal segundo WHARTON; UTECH ${ }^{11}$ (1970), de 25 de junho de 1990) a 8 de agosto de 1991. Para efeito de análise, as contagens foram multiplicadas por dois e calculada a média por grupo em cada contagem.

Em 27 de junho de 1991 foram incorporados aos Grupos I e II, 15 animais substitutos, respectivamente, nove bovinos (três machos e seis fêmeas) e seis bovinos (dois machos $\mathrm{e}$ quatro fêmeas) $3 / 4$ Holandês $x$ Zebu entre seis e dez meses de idade e livres de carrapatos. Os 15 animais, introduzidos inicialmente, foram retirados em 22 de agosto de 1991. permanecendo apenas os animais substitutos. As contagens de carrapatos destes animais foram realizadas no período de 22 de agosto a 26 de dezembro de 1991.

Mais dois animais foram incorporados ao Grupo II, em substituição a três outros que morreram, e as contagens de carrapatos destes procederam a partir de 31 de outubro de 1991, após um mês de contato com o restante do rebanho. Estes animais possuíam 3/4 de sangue Holandês $x$ Zebu e seis a oito meses de idade.

Dados meteorológicos foram obtidos em estação especializada na própria fazenda onde o experimento foi conduzido.

\section{RESULTADOS E DISCUSSÃO}

Na Fig. I estão representados os valores médios das contagens de teleóginas de Boophilus microplus durante todo o período experimental e as épocas dos banhos carrapaticidas efetuados nos animais do Grupo I.

Os dados meteorológicos referentes à temperatura, precipitação pluvial e umidade relativa do ar são representados na Fig. 2.

A escolha da data de início do controle nos animais do Grupo I (cinco banhos estratégicos, com intervalos de 28 dias, a partir de outubro de 1990) baseou-se no fato de que nesta ocasião os picos de teléóginas apresentaram-se altos e com intervalos curtos (FONSECA - trabalho não publicado)***, na elevação das contagens de telégginas apresentadas nos animais antes do tratamento e nos dados meteorológicos observados.

Os banhos com intervalos de 28 dias foram efetuados considerando 21 dias de evolução das larvas deBoophilus microplus a teleóginas e mais 7 dias de efeito residual do Amitraz, o qual mataria as larvas que se fixassem nos animais.
Temperaturas de $15^{\circ} \mathrm{C}$ a $32^{\circ} \mathrm{C}$, umidade relativa do ar de 70 a $90 \%$ ' e precipitaçōes pluviais de 5 a $15 \mathrm{~cm}$ por mês' oferecem condições adequadas para o desenvolvimento embrionário e a sobrevivência larval do Boophilus microplus. Estes parâmetros começaram a ser alcançados a partir da primavera (outubro de 1990) e foram atingidos no verão (janeiro de 1991) (Fig. 2).

O controle estratégico aplicado nos animais do Grupo I apresentou efeito redutor no número de formas adultas de Boophilus microplus. Este resultado talvez possa ser explicado pela eficiência do carrapaticida e do método estratégico de aplicação dos banhos. O reaparecimento das infestaçōes, a niveis baixos, a partir de 04 de abril de 1991, provavelmente deva-se ao fato de que áreas vizinhas ao experimento estavam infestadas e pelo trânsito de animais silvestres que provavelmente invadiram a área experimental. Todavia, as contagens de carrapatos se mantiveram baixas até a primavera de 1991 .

O controle estratégico, por sua vez, não foi suficiente para impedir que os níveis de infestação por teleógina se elevassem nos animais do Grupo I, após o início de condições meteorológicas satisfatórias para o desenvolvimento do Boophilus microplus. As contagens de telcóginas nos animais deste grupo foram aumentando até o final do ano de 1991 e estas se equivaleram às dos animais do Grupo II a partir de dezembro (Fig. 1). Três animais do Grupo II morreram no início da primavera. Espoliaçōes ocasionadas pelos carrapatos e, principalmente, pela infecção por Babesia ssp constatada após esfregaços sanguíneos corados pelo Giemsa foram os possiveis causadores das mortes destes animais. PATARROYO et al. ${ }^{8}$ (1987) encontraram em Viçosa uma prevalência de $66,67 \%$ para Boophilus bovis e $81,82 \%$ para Boophilus bigemina ao teste de imunofluorescência indireta e consideraram-na área de instabilidade enzoótica para babesiose. Estes autores, baseados em estudos de MAHONEY ${ }^{56.7}(1969,1975,1977)$, definiram o Município de Viçosa como área marginal.

Não foi possível verificar o efeito do tipo de pastagem sobre o nível de infestação nos animais, mas segundo THOMPSON et al. ${ }^{10}$ (1978), o Melinis minutiflora apresenta propriedades químicas e biológicas que interferem no desenvolvimento das larvas de carrapato.

\section{CONCLUSÃO}

O controle químico estratégico pela aplicação de banhos carrapaticidas à base de Amitraz, a intervalos de 28 dias, a partir de outubro de 1990 no Município de Viçosa-MG como medida de combate ao Boophilus microplus e, indiretamente, à babesiose, é recomendado. 


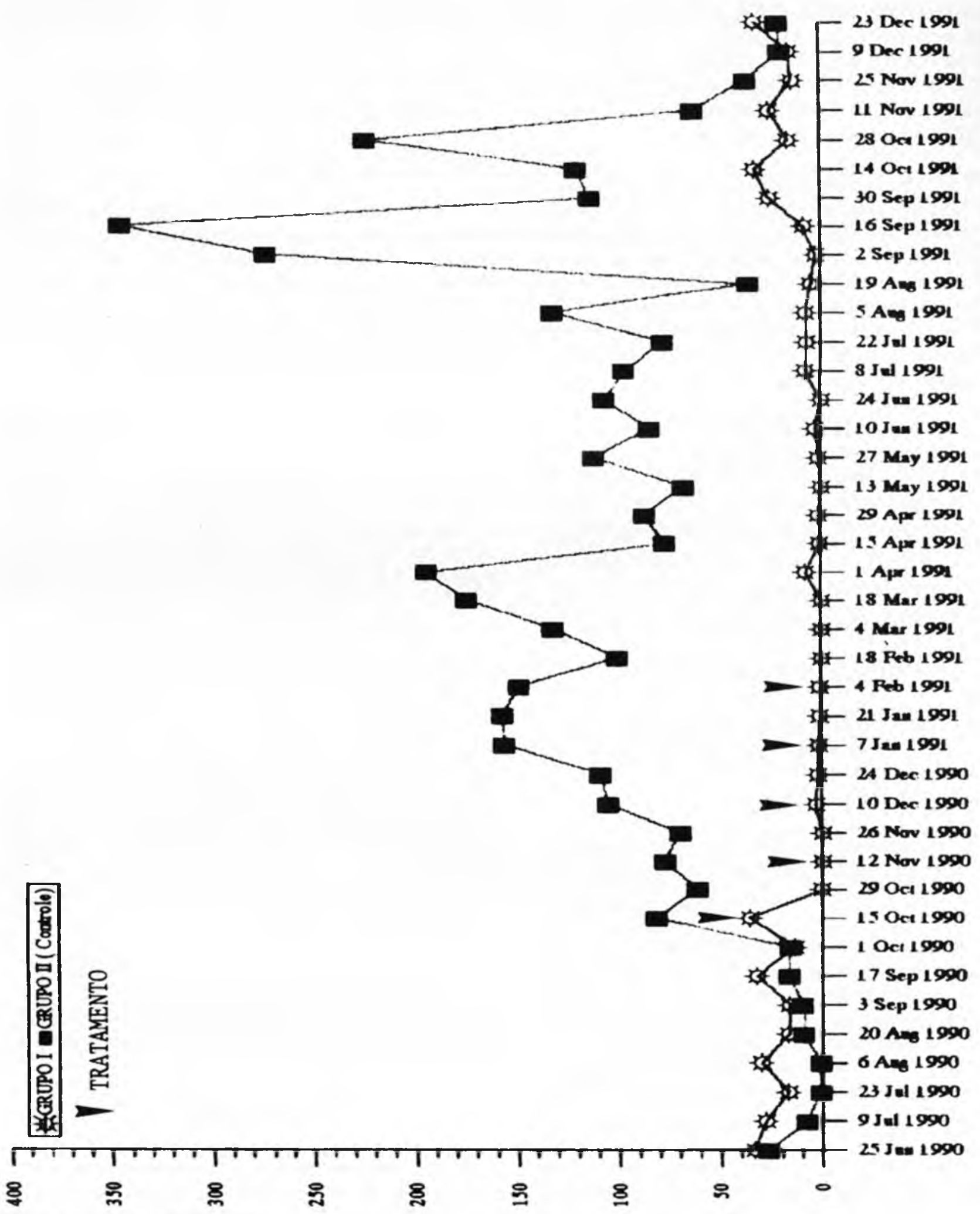

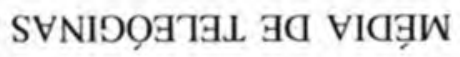

\section{FIC;URA 1}

Valores médios das contagens, a cada 14 dias, de teleóginas de Boophilus microplus em bovinos dos Grupos I e II (controle) em Viçosa-MG, no período de 25 de junho de 1990 a 26 de dezembro de 1991. 


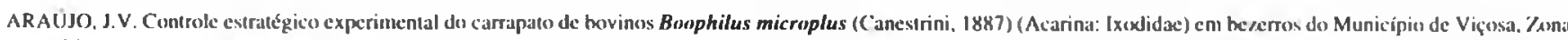
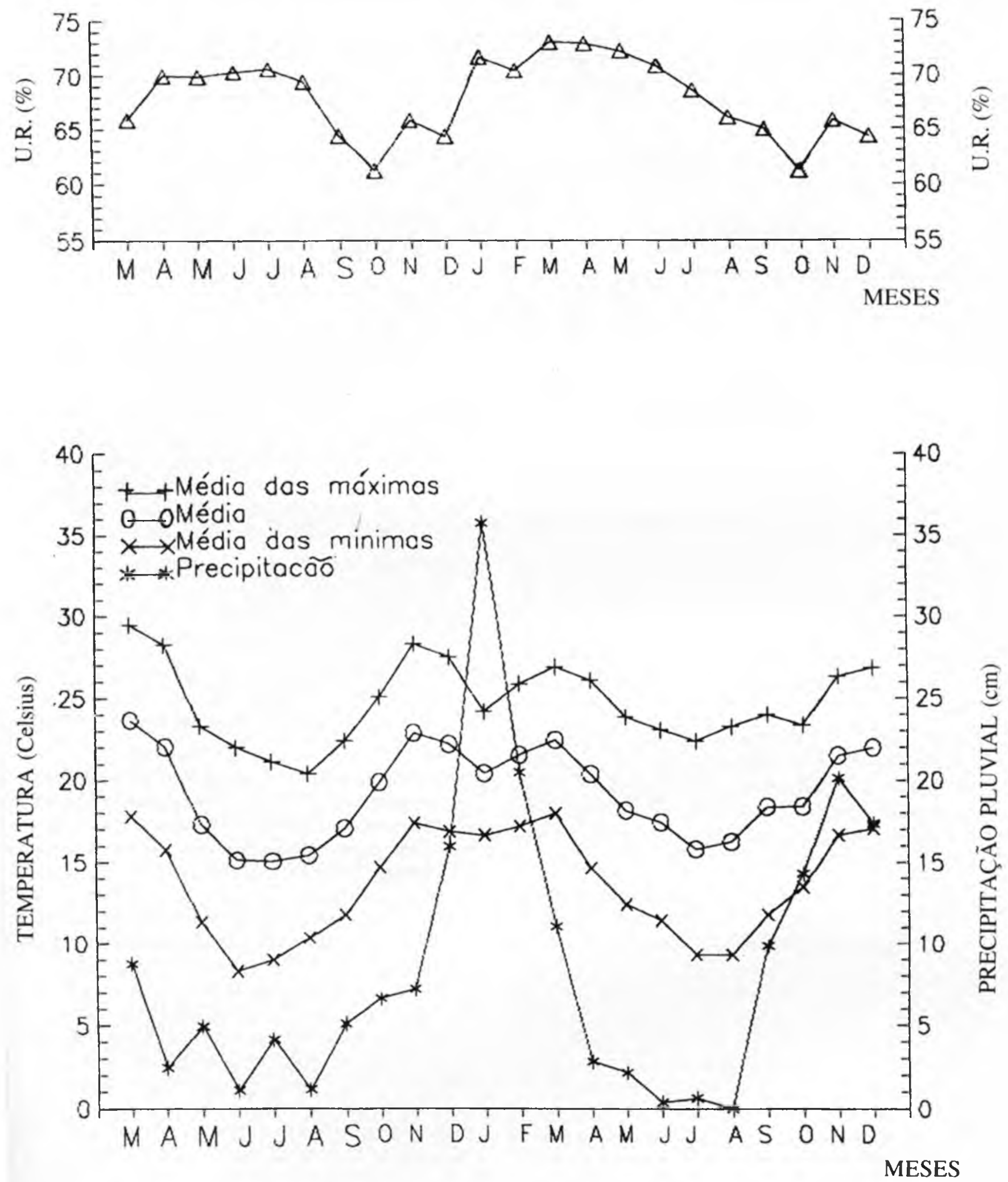

FIGURA 2

Médias das temperaturas mínimas, máximas e médias; precipitação pluvial e UR (Umidade Relativa do Ar) mensais em Viçosa-MG, durante o período de março de 1990 a dezembro de 1991. 


\section{SUMMARY}

The experimental strategic control of the cattle-tick Boophilus microplus on calves ( $3 / 4$ Holstein $\times 1 / 4$ Zebu) from Viçosa was studied by the application of Amitraz, in five spraying done at 28 days intervals from October, 199() to February. 1991. The stablishment of the strategic control system lead to a reduction in adult tick infestation of the animals, but it did not control the increase of the tick number on these animals when meteorological conditions for development of the ticks were satisfactory in the Spring of 1991.

UNITERMS: Metastigmata; Boophilus microplus: Pest control; Calves; Brazil

\section{AGRADECIMENTOS}

Ao $\mathrm{CNPq}$ pelo suporte financeiro, ao funcionário José Geraldo de Oliveira (Tuim) por sua dedicação na realização deste trabalho e ao Departamento de Zootecnia da UFV por ceder os animais.

\section{REFERÊNCIAS BIBLIOGRÁFICAS}

01-HITCHCOCK, L.F. Studies of the non-parasitic stages of the cattle tick, Boophilus microplus (Canestrini) (Acari, Ixodidae). Australian Journal of Zoology. v.3, p.295-311, 1955.

02-HORN, S.C. Prováveis prejuízos causados pelos carrapatos. Boletim de Defesa Sanitária Animal, Brasília, n'esp., 1985. $153 \mathrm{p}$.

03-HORN.S.C.; ANTONIO. R.S.Carrapato, berne e bicheira no Brasil. Brasília, Secretaria de Defesa Agropecuária, 1983.

04-MAGALHÃES, F.E.P. Aspectos biológicos, ecológicos e de controle do Boophilus microplus (Canestrini, 1887) no munícipio de Pedro Leopoldo - Minas Gerais. Belo Horizonte, 1989. Tese (Doutorado) Instituto de Ciências Biológicas, Universidade Federal de Minas Gerais.

05-MAHONEY, D.F. Bovine babesioses: a study of factors, concerned in transmission. Annals of Tropical Medicine and Parasitology, v.63, n.1-14, 1969.
06-MAHONEY, D.F. The diagnosis of babesiosis in Australia. In: WORKSHOP ON HEMOPARASITES, Cali, 1975. Cali, Centro Internacional de Agricultura Tropical, 1975. p.49-62.

07-MAHONEY, D.F. Babesia of domestic animals. In: KREIER. J.P., ed. Parasitic protozoa. New York. Academic Press, 1977. v.4, p.1-52.

08-PATARROYO, S.J.H.; RIBEIRO, M.F.B.; SANTOS, J.L.; FARIA, J.E. Epidemiologia das babesioses bovinas no Estado de Minas Gerais. I. Prevalência de anticorpos fluorescentes na Zona da Mata-MG. Arquivo Brasileiro de Medicina Veterinária e Zootecnia, v.39, n.3, p.423-9, 1987.

09-RAWLINS, S.C. Seasonal variation in the population density of larvae of Boophilus microplus (Canestrini) (Acari-Ixodidae) in Jamaican pastures. Bulletin of Entomological Research. v.69, p.87-91, 1979.

10-THOMPSON, K.C.; ROA, J.; ROMERO, T. Anti-tick grasses as the bases for developing practical tropical tick control packages. Tropical Health Production. v.10, p.179-82, 1978.

II-WHARTON. R.H.; UTECH. K.B.W. The relation between engorgement and dropping of Boophilus microplus (Canestrini) (Ixodidae) to the assessment of tick numbers on cattle. Journal A ustralian Entomological Society, v.9, p.171-82, 1970.

Recebido para publicação em 12/07/93 Aprovado para publicação em 04/02/94 